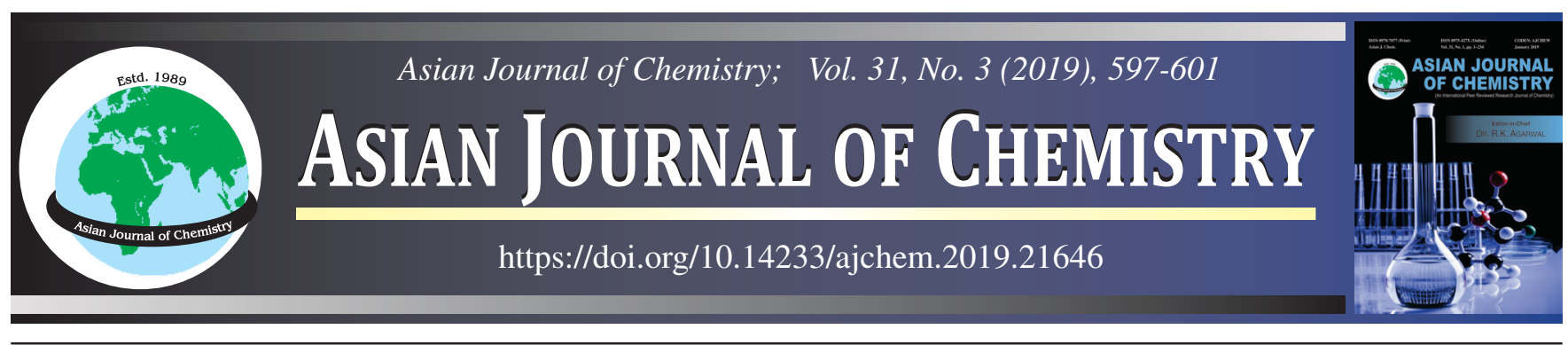

\title{
Theoretical Study of Sigmatropic Rearrangement of Cycloprop-2-en-1-ol and its Fluorine Derivatives: Pericyclic or Pseudopericyclic Character from NICS and LLPE
}

\section{A. Sangeetha ${ }^{1, *}$, A. Thaminum Ansari ${ }^{2}$, Jebakumar Jeevanandam $^{3}$ and S. Jayaprakash ${ }^{4, *}$}

${ }^{1}$ Department of Chemistry, Government Thirumagal Mills College, Gudiyattam-632602, India

${ }^{2}$ PG \& Research Department of Chemistry, Muthurangam Government Arts College (Autonomous), Vellore-632002, India

${ }^{3}$ Department of Chemistry, Rajeswari Vedachalam Government Arts College, Chengalpet-603001, India

${ }^{4}$ Department of Chemistry, Islamiah College, Vaniyambadi-635752, India

*Corresponding authors: E-mail: s.jayaprakash004@gmail.com; a.sangeetha1502@gmail.com

Received: 13 August 2018;

Accepted: 31 October 2018;

Published online: 31 January 2019;

AJC-19252

\begin{abstract}
Sigmatropic rearrangement reaction of cycloprop-2-en-1-ol and its fluorine derivatives has been studied theoretically in gas phase and its energy barrier has been calculated. Nucleus-independent chemical shift (NICS) shows sigmatropic rearrangement of cycloprop-2-en-1-ol is pericyclic in nature whereas fluorine derivatives show pseudopericyclic and pericyclic nature. Substitution of fluorine atom at ring is found to increase the energy barrier for $-\mathrm{OH}$ migration, while substitution at oxygen atom reduces the barrier. To know the involvement of lone pair of electrons during the reaction, lone pair electron present on oxygen atom is locked by hydrogen bonding. CR-CCSD(T)/6$311+\mathrm{G}^{* *}$ levels are used to study the reactions more accurately.
\end{abstract}

Keywords: Pseudopericyclic reaction, Aromaticity, DFT calculations, ab initio calculations, Sigmatropic rearrangement reaction. ᄂ

\section{INTRODUCTION}

All the reactions in organic chemistry do not involve intermediates. Absence of intermediates indicates that the reactions in which bond making and breaking takes place by single step process called concerted reaction and that particular class of concerted reactions called pericyclic reaction [1]. Pericyclic reactions involve cyclic transition states. Woodward and Hoffmann [2] showed that symmetry of the orbitals that are involved in a reaction decide the mechanism of that particular reaction. In pericyclic reaction the lone pair electron on heteroatom, which take part in the cyclic transition state known as pseudopericyclic reactions [3-18]. Since there is no clear cut criteria exist to differentiate a pericyclic reaction from a pseudo-pericyclic one, some reactions have difficulty in being classified [19-23]. The magnetic property study is helpful to assess the extent of aromatization along the reaction path [2436 ] and also helps in quantifying reactions as pericyclic or pseudo-pericyclic.

In this manuscript we have presented a comprehensive theoretical study of the sigmatropic rearrangement (SR) reaction of cycloprop-2-en-1-ol. The principle mechanism of this reaction governs the fluxional behaviour of oxygen during the $[1,3]$ sigmatropic shift. Particularly the lone pair of electron on oxygen atom alter the $[1,3]$ sigmatropic shift of $-\mathrm{OH}$ by pericyclic/ pseudopericyclic mechanism. To know how extent the lone pair of electron involved in the reaction, we extended the SR reaction to fluorine substitution in place of hydrogen atoms attached to cyclic ring and the hydrogen attached to the oxygen atom. To differentiate the pericyclic/pseudopericyclic nature of a reaction, locking of lone pair of electrons (LLPE) [37,38] is used in addition to nucleus-independent chemical shift (NICS).

\section{COMPUTATIONAL METHODS}

Sigmatropic rearrangement reaction of cycloprop-2-en-1ol was studied using ab initio molecular orbital and density functional theory at various level of calculations. The computations were performed at MP2/6-311+G**, B3LYP/6-311+G** and CR-CCSD(T)/6-311+G** [39-41] levels of calculation. Firefly [42] and the GAMESS (US) [43] program were used for the

This is an open access journal, and articles are distributed under the terms of the Creative Commons Attribution-NonCommercial-ShareAlike 4.0 (CC BY-NC-SA 4.0) International License which allows readers to freely read, download, copy, distribute, print, search, or link to the full texts of its articles and to use them for any other lawful non-commercial purpose as long as the original source is duly acknowledged. 
computations. In all cases, the structure of reactant, transition state and the product were completely optimized. From the transition state structure, intrinsic reaction coordinates (IRC) calculations were carried out. Hessian calculations were done and the frequencies for reactants and products were found to be real values and the transition states have one imaginary frequency. NICS calculation were performed at B3LYP/6-311+G** basis using the gauge including atomic orbital method [44] (GIAO) in GAUSSIAN-03 [45] package. The magnetic shielding tensor calculations were carried out by placing the ghost atom at the ring critical points (RCP) at the lowest electron density in the ring plane [46-49]. NICS calculations were carried out to measure the value of aromaticity due to $\pi$-system and sometimes obscured by the $\sigma$-current. MacMolplt [50] software is used to visualize the graphical outputs.

\section{RESULTS AND DISCUSSION}

In the SR reaction of cycloprop-2-en-1-ol, 1,2,3-trifluorocycloprop-2-en-1-ol, 1,2,3-trifluorocycloprop-2-en-1-yl hypofluorite, cycloprop-2-en-1-yl hypofluorite, the energy of the reactant, transition state and the product were calculated and are given in Table-1. It is seen that in the SR reaction of cycloprop-2-en-1-ol the [1,3] shift of hydroxy group takes by two modes and it was studied using B3LYP/6-311+G** and MP2/6-311+G** levels of calculation (Fig. 1). Mode I and mode II are asymmetric transition states and both are first order saddle points $\left(671.57\right.$ and $\left.601.10 i \mathrm{~cm}^{-1}\right)$. In mode I the hydrogen atom of the migrating $\mathrm{OH}$ group is inside the ring while in mode II it is outside in the transition state. In both cases the IRC computation connects the transition state to its particular reactant and product. It is of interest to note that CR-CCSD(T)/6-311+G** calculation shows migration by mode II only. The transition state of the SR reaction of cycloprop-2en-1-ol has one imaginary frequency and its value is $601.10 i$ $\mathrm{cm}^{-1}$ calculated at CR-CCSD(T)/6-311+G** level of calculation. In SR reaction of 1,2,3-trifluorocycloprop-2-en-1-ol the $[1,3]$ shift of hydroxy group takes place by two modes. The two transition states (Mode I and Mode II) have one imaginary frequency each, 764.22 and $756.82 i \mathrm{~cm}^{-1}$ calculated at the B3LYP/6-311+G** level of calculation. $[1,3]$ shift of hypofluorite group in 1,2,3-trifluorocycloprop-2-en-1-yl hypofluorite, cycloprop-2-en-1-yl hypofluorite takes place by mode II and its imaginary frequencies are 481.11 and

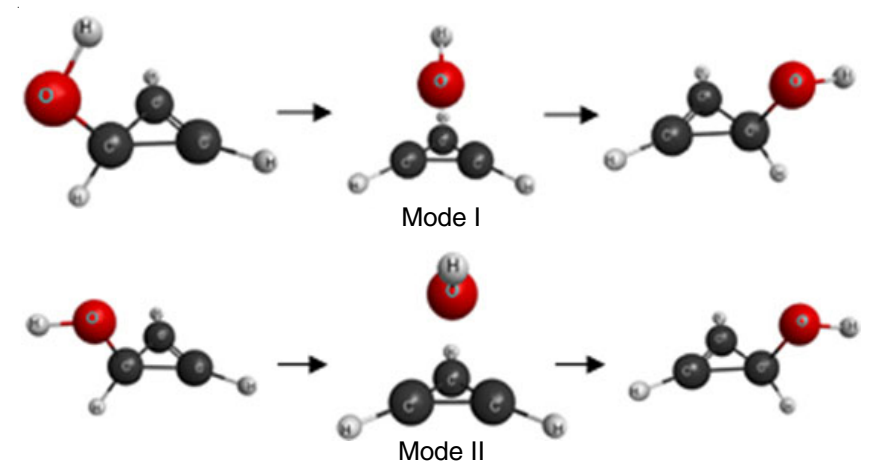

Fig. 1. Structure of the reactant, transition state and product of the SR reaction of cycloprop-en-1-ol

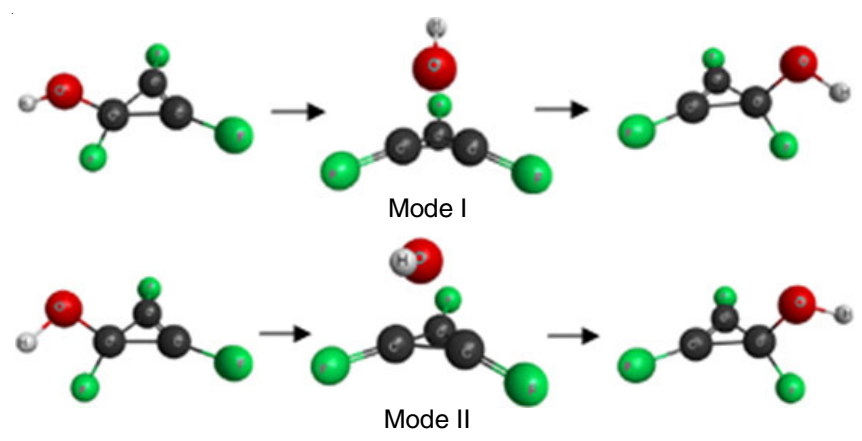

Fig. 2. Structure of the reactant, transition state and product of the SR reaction of 1,2,3-trifluorocycloprop-2-en-1-ol

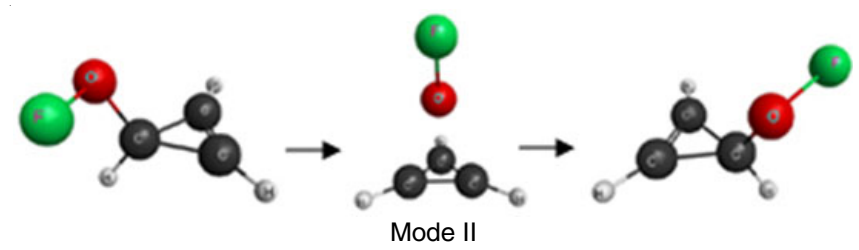

Fig. 3. Structure of the reactant, transition state and product of the SR reaction of cycloprop-2-en-1-yl hypofluorite

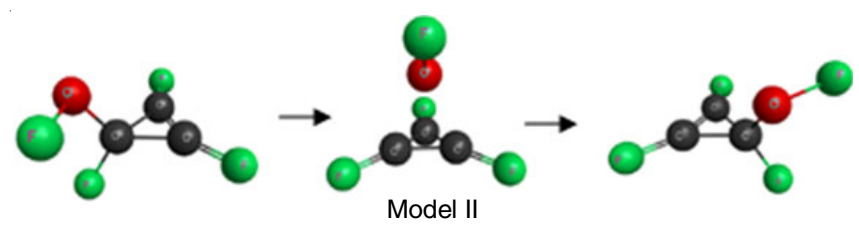

Fig. 4. Structure of the reactant, transition state and product of the SR reaction of 1,2,3-trifluorocycloprop-2-en-1-yl hypofluorite

TABLE-1

ENERGIES FOR THE SIGMATROPIC REARRANGEMENT OF CYCLOPROP-2-EN-1-OL AND ITS FLUORINE DERIVATIVES

\begin{tabular}{|c|c|c|c|c|c|}
\hline Levels of calculations & {$[1,3]$ Sigmatropic shift } & $\begin{array}{l}\text { Reactant } \\
\text { (hartrees) }\end{array}$ & $\begin{array}{c}\text { Transition state } \\
\text { (hartrees) }\end{array}$ & $\begin{array}{l}\text { Product } \\
\text { (hartrees) }\end{array}$ & $\begin{array}{c}\text { Energy barrier } \\
\quad\left(\mathrm{kcal} \mathrm{mol}^{-1}\right)\end{array}$ \\
\hline \multirow[t]{2}{*}{$\mathrm{MP} 2 / 6-311+\mathrm{G}^{* *}$} & $-\mathrm{OH}$ in $\mathrm{C}_{3} \mathrm{H}_{4} \mathrm{O}$ Mode-I & -191.3703140 & -191.2793527 & -191.3703140 & 57.1 \\
\hline & $-\mathrm{OH}$ in $\mathrm{C}_{3} \mathrm{H}_{4} \mathrm{O}$ Mode-II & -191.3703140 & -191.2787337 & -191.3697821 & 57.5 \\
\hline \multirow[t]{2}{*}{ B3LYP/6-311+G** } & $-\mathrm{OH}$ in $\mathrm{C}_{3} \mathrm{H}_{4} \mathrm{O}$ Mode- $\mathrm{I}$ & -191.9051017 & -191.8219254 & -191.9051017 & 52.5 \\
\hline & -OH in $\mathrm{C}_{3} \mathrm{H}_{4} \mathrm{O}$ Mode-II & -191.9050157 & -191.8241093 & -191.9050157 & 50.8 \\
\hline CR-CCSD(T)/6-311+G** & -OH in $\mathrm{C}_{3} \mathrm{H}_{4} \mathrm{O}$ Mode-II & -191.4102627 & -191.3103909 & -191.4102627 & 62.7 \\
\hline \multirow[t]{2}{*}{ B3LYP/6-311+G** } & -OH in $\mathrm{C}_{3} \mathrm{~F}_{3} \mathrm{OH}$ Mode- $\mathrm{I}$ & -489.7013068 & -489.5959475 & -489.7013068 & 66.1 \\
\hline & $-\mathrm{OH}$ in $\mathrm{C}_{3} \mathrm{~F}_{3} \mathrm{OH}$ Mode-II & -489.7013109 & -489.5969053 & -489.7013109 & 65.5 \\
\hline B3LYP/6-311+G** & -OF in $\mathrm{C}_{3} \mathrm{~F}_{3} \mathrm{OF}$ Mode-II & -588.8415902 & -588.7591953 & -588.8415902 & 51.7 \\
\hline B3LYP/6-311+G** & -OF in $\mathrm{C}_{3} \mathrm{H}_{3} \mathrm{OF}$ Mode-II & -291.0605847 & -290.9968383 & -291.0605847 & 40.0 \\
\hline B3LYP/6-311+G** & $-\mathrm{CH}_{3}$ in $\mathrm{C}_{4} \mathrm{H}_{6}$ PARENT & -155.9842139 & -155.8447105 & -155.9842627 & 87.5 \\
\hline B3LYP/6-311+G** & -OH in $\mathrm{C}_{3} \mathrm{H}_{4} \mathrm{O}$ Mode-II with LLPE & -268.3736518 & -268.3036247 & -268.3736518 & 43.9 \\
\hline B3LYP/6-311+G** & $-\mathrm{OH}$ in $\mathrm{C}_{3} \mathrm{~F}_{3} \mathrm{OH}$ Mode-II with LLPE & -566.1663815 & -566.0698659 & -566.1663815 & 60.6 \\
\hline
\end{tabular}


$309.80 i \mathrm{~cm}^{-1}$ calculated at the B3LYP/6-311+G** level of calculation.

Pericyclic/pseudopericyclic reactions: For a better understanding of the SR reaction of cycloprop-2-en-1-ol, 1,2,3trifluorocycloprop-2-en-1-ol, 1,2,3-trifluorocycloprop-2-en-1yl hypofluorite, cycloprop-2-en-1-yl hypofluorite first we analyzed [1,3] sigmatropic shift of methylene in 3-methylcyclopropene, it was considered as the parent SR reaction as shown in Fig. 5. From the point of Birney et al. [4-8] pseudopericyclic reaction have low activation energy and disconnection in orbital overlap in the transition state which leads to lower aromaticity. The barrier for the methyl group migration in cyclopropene ring has been computed to be $87.5 \mathrm{kcal} \mathrm{mol}^{-1}$ (Table-1). At the B3LYP/6-311+G** level calculation the transition state has one imaginary frequency $\left(1021.64 i \mathrm{~cm}^{-1}\right)$ and IRC computation connects the transition state into its particular reactant and product. Comparing the energy barrier of $[1,3]$ sigmatropic shift of methylene with [1,3] sigmatropic shift of hydroxy and hypofluorite group it is seen that the methylene migration in the parent hydrocarbon has a much higher barrier than the substituted compounds. The lower activation energy barrier of SR shifts of hydroxy and hypofluorite group shows pseudopericyclic nature. But the low activation energy may be due to presence of reactive oxygen atom. NICS and LLPE methods are used to study pericyclic/pseudopericyclic character more accurately.

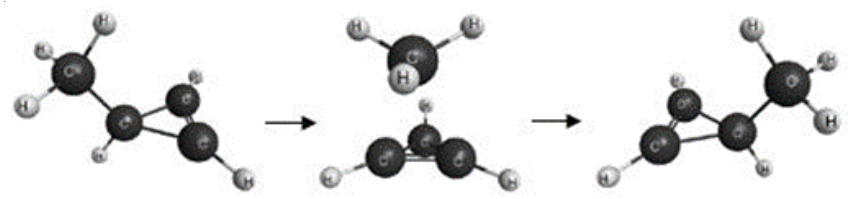

Fig. 5. Structure of the reactant, transition state and product of the SR reaction of 3-methylcyclopropene

Nucleus-independent chemical shift (NICS): In this SR studies, NICS calculations were carried out by placing ghost atom in the geometrical center of the three-member ring to a set of point $1 \AA$ below the ring to avoid the effects of $\sigma$ bonds [51] and also the spurious effect associated with lone pair of electrons present in oxygen atom above the ring as shown in Fig. 1. NICS calculation was carried out for both transition states and reactants to study the differences between them. The results are plotted in Fig. 6. The NICS computations show that the SR reaction of cycloprop-2-en-1-ol is pericyclic in nature, because of enhanced aromaticity. If the reaction was pseudopericyclic, the involvement of the lone pair of electrons on the oxygen atom during the transition state would reduce the aromaticity of the ring.

When hydrogen bonding is used to lock the lone pair of electrons present in the oxygen atom, the involvement of lone pair in the cyclic transition is blocked and hence the aromaticity is increased, compared to the aromaticity value calculated without LLPE. Using the points from 0.4 to $1.0 \AA$ below the ring as the reference points, the NICS values calculated at the transition state when lone pair electron is locked shows slightly increase in aromaticity. This shows on hydrogen bonding the lone pair of electrons is not completely available to take part in the cyclic transition and also the slight increase in aromaticity

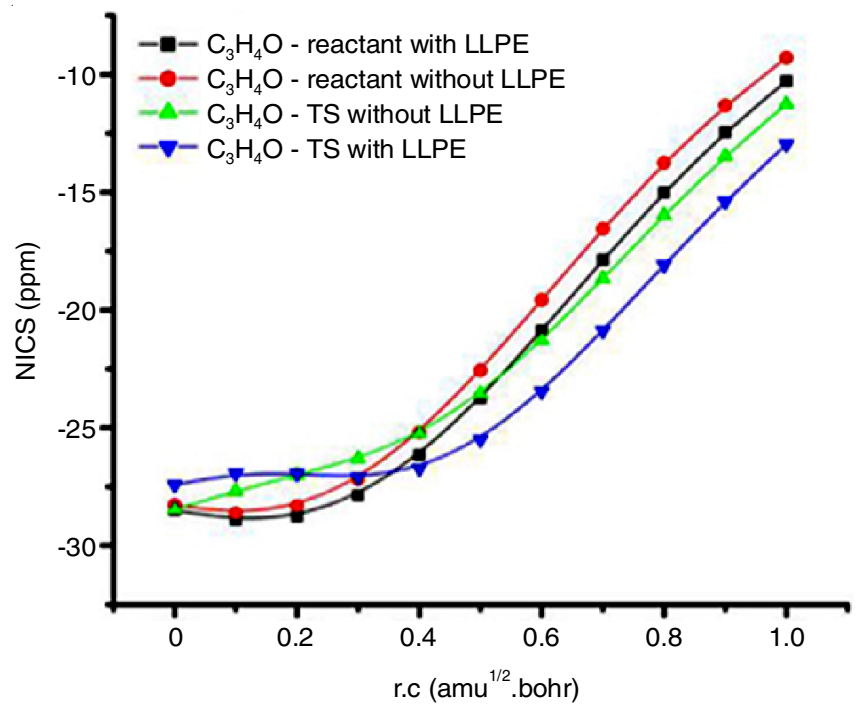

Fig. 6. NICS values for SR reaction of cycloprop-2-en-1-ol, with and without LLPE calculated at B3LYP/6-311+G** level of calculation

indicates a shift towards pericyclic nature. For the SR reaction of hydroxyl group shift in cycloprop-2-en-1-ol at the B3LYP/ $6-311+\mathrm{G}^{* *}$ level of calculation, when the lone pair is locked, the energy barrier is reduced by $6.9 \mathrm{kcal} \mathrm{mol}^{-1}$. To understand the involvement of lone pair present on the oxygen atom, NICS calculations were carried out for the fluorine derivatives of cycloprop-2-en-1-ol. In the SR reaction of 1,2,3-trifluorocycloprop-2-en-1-ol, NICS values shows lower value of aromaticity and is plotted in Fig. 7. The substitution of three fluorine atoms causes the withdrawal of the $\pi$ electrons. Due to the lower availability of $\pi$ electrons for migration, the lone pair of electrons present on the oxygen atom gets more involved in reaction. Hence the pseudopericyclic character is increased. NICS computations with and without LLPE, show increased aromaticity on locking the lone pairs. Also the lowering of barrier by 4.9 $\mathrm{kcal} \mathrm{mol}^{-1}$ during locking confirms the involvement of the lone pairs.

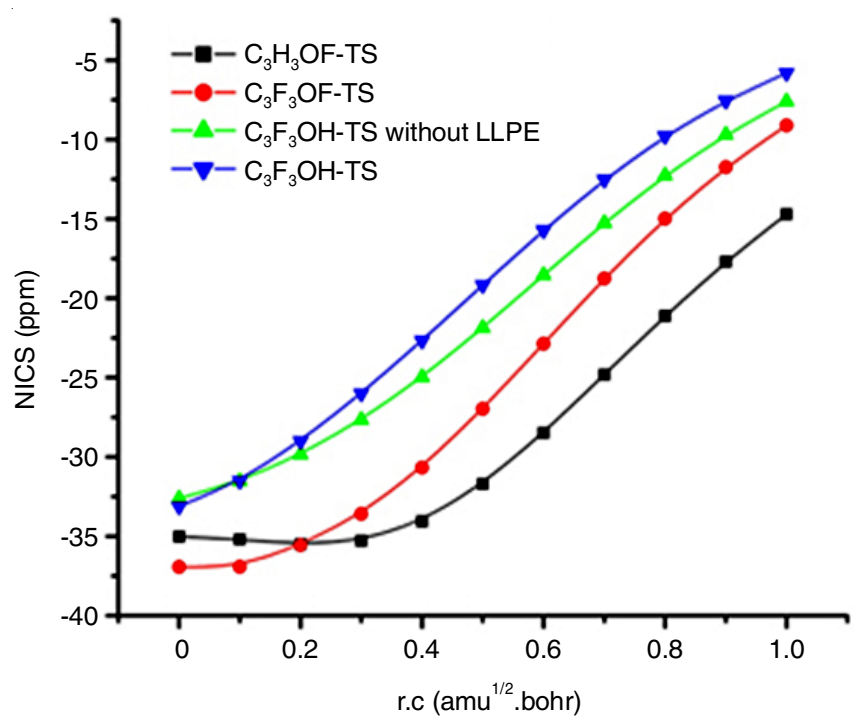

Fig. 7. NICS values for SR reaction of 1,2,3-trifluorocycloprop-2-en-1-ol, 1,2,3-trifluorocycloprop-2-en-1-yl hypofluorite and cycloprop-2en-1-yl hypofluorite, with and without LLPE calculated at B3LYP/ $6-311+\mathrm{G}^{* *}$ level of calculation 
In the SR reaction of cycloprop-2-en-1-yl hypofluorite the $[1,3]$ sigmatropic shift of hypofluorite group shows the lowest barrier for all the migrations considered in this study, having a value of $40 \mathrm{kcal} \mathrm{mol}^{-1}$. The NICS curves show maximum aromaticity which tallies with this observation. When replacing hydrogen atom in $\mathrm{OH}$ by fluorine, the electronegative nature of fluorine makes the lone pair of electrons (on the oxygen atom) less available during the migration. Hence this SR is most pericyclic in nature. In the case of the SR of 1,2,3-trifluorocycloprop-2-en-1-yl hypofluorite the ring fluorine atom and the hypofluorite group play opposing roles. Substitution of fluorine atoms in the ring increases the activation barrier by $15 \mathrm{kcal} \mathrm{mol}^{-1}$ for the three fluorine atoms. Migration of 'OF' instead of ' $\mathrm{OH}$ ' reduces the barrier by $10 \mathrm{kcal} \mathrm{mol}^{-1}$ because the $\mathrm{C}-\mathrm{O}$ bond in $\mathrm{C}-\mathrm{OF}$ is more easily broken than in $\mathrm{C}-\mathrm{OH}$. The bond order computed at B3LYP/6-311+G** is found to show a linear trend with the migration barrier. This results in 'OF' sigmatropic migration in $\mathrm{C}_{3} \mathrm{~F}_{3} \mathrm{OF}$ to have a barrier $(51.7 \mathrm{kcal}$ mol $^{-1}$ ) between that of $\mathrm{C}_{3} \mathrm{H}_{3} \mathrm{OH}$ and $\mathrm{C}_{3} \mathrm{~F}_{3} \mathrm{OH}$. The NICS curves also show the same trend.

\section{Conclusion}

Sigmatropic rearrangement (SR) reaction of cycloprop2-en-1-ol and its fluorine derivatives was studied using ab initio molecular orbital and density functional theory. Transition state and energy barrier were calculated at different levels of calculation. The SR reaction of cycloprop-2-en-1-ol and its fluorine derivatives are comparing with 1-methyl cyclopropene, the lower activation energy is due to presence of oxygen atom. To investigate the behaviour of aromaticity, the NICS profiles have been computed. On the basis of NICS profile the SR reaction of cycloprop-2-en-1-ol, cycloprop-2-en-1-yl hypofluorite and 1,2,3-trifluorocycloprop-2-en-1-yl hypofluorite was found to pericyclic in nature, whereas SR reaction of 1,2,3-trifluorocycloprop-2-en-1-ol is pseudopericyclic. Substitution of fluorine atoms on the ring results in withdrawal of $\pi$ electrons causing the migrating oxygen atom to donate more of its electrons to the sigmatropic migration. This results in increasing pseudopericyclic nature. Replacement of hypofluorite group in the place of the hydroxyl group results in pericyclic nature as the $\mathrm{C}-\mathrm{O}$ bond in ' $\mathrm{C}-\mathrm{OF}$ ' is more easily broken than in ' $\mathrm{C}-\mathrm{OH}$ ' and also because of the electron withdrawing nature of the fluorine atom. Substitution of fluorine atoms both at the ring and at the oxygen atom has opposing effects and the SR reaction is mildly pericyclic. CR-CCSD(T)/6-311+G** level calculation were carried out to appraise the energies of the reaction more accurately.

\section{ACKNOWLEDGEMENTS}

One of the authors S. Jayaprakash thanks the Department of Chemistry, Islamiah College, Vaniyamabadi, for providing partial computer time.

\section{CONFLICT OF INTEREST}

The authors declare that there is no conflict of interests regarding the publication of this article.

\section{REFERENCES}

1. F.A. Carey and R.J. Sundberg, Advanced Organic Chemistry Part A: Structure and Mechanisms, Springer Science Business Media Inc.: New York (2000).

2. R.B. Woodward, R. Hoffmann, The Conservation of Orbital Symmetry. Verlag-Chemie GmbG, Academic Press Inc.: Weinheim/Bergstr, edn 1 (1971).

3. J.A. Ross, R.P. Seiders and D.M. Lemal, J. Am. Chem. Soc., 98, 4325 (1976); https://doi.org/10.1021/ja00430a060.

4. D.M. Birney and P.E. Wagenseller, J. Am. Chem. Soc., 116, 6262 (1994); https://doi.org/10.1021/ja00093a028.

5. D.M. Birney, S. Ham and G.R. Unruh, J. Am. Chem. Soc., 119, 4509 (1997); https://doi.org/10.1021/ja963551r.

6. D.M. Birney, J. Am. Chem. Soc., 122, 10917 (2000); https://doi.org/10.1021/ja0020005.

7. W.W. Shumway, N.K. Dalley and D.M. Birney, J. Org. Chem., 66, 5832 (2001); https://doi.org/10.1021/jo015698t.

8. C. Zhou and D.M. Birney, J. Am. Chem. Soc., 124, 5231 (2002); https://doi.org/10.1021/ja017559z.

9. L. Luo, M.D. Bartberger and W.R.J. Dolbier, J. Am. Chem. Soc., 119, 12366 (1997); https://doi.org/10.1021/ja972701a.

10. W.M.F. Fabian, V.A. Bakulev and C.O. Kappe, J. Org. Chem., 63, 5801 (1998); https://doi.org/10.1021/jo980238u.

11. W.M.F. Fabian, C.O. Kappe and V.A. Bakulev, J. Org. Chem., 65, 47 (2000); https://doi.org/10.1021/jo990997s.

12. M. Alajarin, A. Vidal, P. Sanchez-Andrada, F. Tovar and G. Ochoa, Org. Lett., 2, 965 (2000); https://doi.org/10.1021/o10056168.

13. G. Rauhut, J. Org. Chem., 66, 5444 (2001); https://doi.org/10.1021/jo010307w.

14. E. Chamorro, J. Chem. Phys., 118, 8687 (2003); https://doi.org/10.1063/1.1566740.

15. J.J. Finnerty and C. Wentrup, J. Org. Chem., 69, 1909 (2004); https://doi.org/10.1021/jo035419x.

16. M. Zora, J. Org. Chem., 69, 1940 (2004); https://doi.org/10.1021/jo035548d.

17. J. Kalcher and W.M.F. Fabian, Theor. Chem. Acc., 109, 195 (2003); https://doi.org/10.1007/s00214-002-0410-6.

18. E.E. Chamorro and R. Notario, J. Phys. Chem. A, 108, 4099 (2004); https://doi.org/10.1021/jp049847y.

19. A.R. de Lera, R. Alvarez, B. Lecea, A. Torrado and F.P. Cossio, Angew. Chem. Int. Ed., 40, 557 (2001); https://doi.org/10.1002/1521-3773(20010202)40:3<557::AIDANIE557>3.0.CO;2-T.

20. J.R. -Otero and E.M. Cabaleiro-Lago, Angew. Chem. Int. Ed., 41, 1147 (2002); https://doi.org/10.1002/1521-3773(20020402)41:7<1147::AIDANIE1147>3.0.CO:2-J.

21. A.R. de Lera and F.P. Cossio, Angew. Chem. Int. Ed., 41, 1150 (2002); https://doi.org/10.1002/1521-3773(20020402)41:7<1150::AIDANIE1150>3.0.CO;2-M.

22. J. Rodríguez-Otero and E.M. Cabaleiro-Lago, Chem. Eur. J., 9, 1837 (2003); https://doi.org/10.1002/chem.200390211.

23. E. Matito, J. Poater, M. Duran and M. Sola, ChemPhysChem, 7, 111 (2006); https://doi.org/10.1002/cphc.200500446.

24. H.E. Zimmerman, Acc. Chem. Res., 4, 272 (1971); https://doi.org/10.1021/ar50044a002.

25. R. Herges, H. Jiao and P. von Ragué Schleyer, Angew. Chem. Int. Ed. Engl., 33, 1376 (1994); https://doi.org/10.1002/anie.199413761.

26. H. Jiao and P.R. Schleyer, J. Phys. Org. Chem., 11, 655 (1998); https://doi.org/10.1002/(SICI) 1099-1395(199808/09)11:8/ 9<655::AID-POC66>3.0.CO;2-U.

27. M. Manoharan, F. De Proft and P. Geerlings, J. Org. Chem., 65, 7971 (2000); https://doi.org/10.1021/jo001156k. 
28. M. Manoharan, F. De Proft and P. Geerlings, J. Chem. Soc., Perkin Trans. 2, 8, 1767 (2000); https://doi.org/10.1039/b002344m.

29. A.C. Tsipis, C.E. Kefalidis and C.A. Tsipis, J. Am. Chem. Soc., 130, 9144 (2008); https://doi.org/10.1021/ja802344z.

30. A.C. Tsipis and C.A. Tsipis, J. Am. Chem. Soc., 125, 1136 (2003); https://doi.org/10.1021/ja028786j.

31. C.A. Tsipis, E.E. Karagiannis, P.F. Kladou and A.C. Tsipis, J. Am. Chem. Soc., 126, 12916 (2004); https://doi.org/10.1021/ja0469277.

32. C.S. Wannere, C. Corminboeuf, Z.-X. Wang, M.D. Wodrich, R.B. King and P.R. Schleyer, J. Am. Chem. Soc., 127, 5701 (2005); https://doi.org/10.1021/ja042716q.

33. C. Corminboeuf, C.S. Wannere, D. Roy, R.B. King and P.R. Schleyer, Inorg. Chem., 45, 214 (2006); https://doi.org/10.1021/ic051576y.

34. G.H. Zhang, Y.F. Zhao, J.I. Wu and P.R. Schleyer, Inorg. Chem., 48, 6773 (2009); https://doi.org/10.1021/ic900718t

35. Z. Chen, C. Corminboeuf, T. Heine, J. Bohmann and P.R. Schleyer, J. Am. Chem. Soc., 125, 13930 (2003); https://doi.org/10.1021/ja0361392.

36. P.R. Schleyer, C. Maerker, A. Dransfeld, H. Jiao and N.J.R. van Eikema Hommes, J. Am. Chem. Soc., 118, 6317 (1996); https://doi.org/10.1021/ja960582d.

37. S. Jayaprakash, J. Jeevanandam and K. Subramani, J. Mol. Model., 20, 2494 (2014); https://doi.org/10.1007/s00894-014-2494-Z.

38. S. Jayaprakash, J. Jeevanandam, K. Subramani and A. Sangeetha, Comput. Theor. Chem., 1056, 52 (2015); https://doi.org/10.1016/j.comptc.2015.01.004.

39. P. Piecuch, S.A. Kucharski, K. Kowalski and M. Musial, Comput. Phys. Commun., 149, 71 (2002); https://doi.org/10.1016/S0010-4655(02)00598-2.

40. K. Kowalski and P. Piecuch, J. Chem. Phys., 113, 18 (2000); https://doi.org/10.1063/1.481769.

41. K. Kowalski and P. Piecuch, J. Chem. Phys., 113, 5644 (2000); https://doi.org/10.1063/1.1290609.

42. P.C. Alex Granovsky, GAMESS/Firefly version 7.1.F; http://classic.chem.msu.su/gran/gamess/index.html.
43. M.W. Schmidt, K.K. Baldridge, J.A. Boatz, S.T. Elbert, M.S. Gordon, J.H. Jensen, S. Koseki, N. Matsunaga, K.A. Nguyen, S.J. Su, T.L. Windus, M. Dupuis and J.A. Montgomery, J. Comput. Chem., 14, 1347 (1993); https://doi.org/10.1002/jcc.540141112.

44. K. Wolinski, J.F. Hinton and P. Pulay, J. Am. Chem. Soc., 112, 8251 (1990); https://doi.org/10.1021/ja00179a005.

45. M.J. Frisch, G.W. Trucks, H.B. Schlegel, G.E. Scuseria, M.A. Robb, J.R. Cheeseman, J.A. Montgomery Jr., T. Vreven, K.N. Kudin, J.C. Burant, J.M. Millam, S.S. Iyengar, J. Tomasi, V. Barone, B. Mennucci, M. Cossi, G. Scalmani, N. Rega, G.A. Petersson, H. Nakatsuji, M. Hada, M. Ehara, K. Toyota, R. Fukuda, J. Hasegawa, M. Ishida, T. Nakajima, Y. Honda, O. Kitao, H. Nakai, M. Klene, X. Li, J.E. Knox, H.P. Hratchian, J.B. Cross, C. Adamo, J. Jaramillo, R. Gomperts, R.E. Stratmann, O. Yazyev, A.J. Austin, R. Cammi, C. Pomelli, J.W. Ochterski, P.Y. Ayala, K. Morokuma, G.A. Voth, P. Salvador, J.J. Dannenberg, V.G. Zakrzewski, S. Dapprich, A.D. Daniels, M.C. Strain, O. Farkas, D.K. Malick, A.D. Rabuck, K. Raghavachari, J.B. Foresman, J.V. Ortiz, Q. Cui, A.G. Baboul, S. Clifford, J. Cioslowski, B.B. Stefanov, G. Liu, A. Liashenko, P. Piskorz, I. Komaromi, R.L. Martin, D.J. Fox, T. Keith, M.A. Al-Laham, C.Y. Peng, A. Nanayakkara, M. Challacombe, P.M.W. Gill, B. Johnson, W. Chen, M.W. Wong, C. Gonzalez and J.A. Pople, Gaussian, Inc.: Wallingford CT (2004).

46. R.F.W. Bader, Atoms in Molecules, A Quantum Theory, Clarendon: Oxford (1990)

47. F.P. Cossio, I. Morao, H.J. Jiao and P.R. Schleyer, J. Am. Chem. Soc., 121, 6737 (1999); https://doi.org/10.1021/ja9831397.

48. P.R. Schleyer, M. Manoharan, H.J. Jiao and F. Stahl, Org. Lett., 3, 3643 (2001) https://doi.org/10.1021/ol016553b.

49. C. Corminboeuf, T. Heine, G. Seifert, P.R. Schleyer and J. Weber, Phys. Chem. Chem. Phys., 6, 273 (2004); https://doi.org/10.1039/B313383B.

50. B.M. Bode and M.S. Gordon, J. Mol. Graph. Model., 16, 133 (1998); https://doi.org/10.1016/S1093-3263(99)00002-9.

51. P.R. Schleyer, M. Manoharan, Z.X. Wang, B. Kiran, H. Jiao, R. Puchta and N.J.R. van Eikema Hommes, Org. Lett., 3, 2465 (2001); https://doi.org/10.1021/o1016217v. 